Cipango $\begin{aligned} & \text { Cipango } \\ & \text { Cahiers d'études japonaises }\end{aligned}$

$18 \mid 2011$

Le Japon et le fait colonial I

\title{
Le temps et l'espace dans les récits de guerre de Shimao Toshio
}

\section{Yannick Maufroid}

\section{(2) OpenEdition}

1 Journals

\section{Édition électronique}

URL : https://journals.openedition.org/cipango/1626

DOI : 10.4000/cipango.1626

ISSN : 2260-7706

\section{Éditeur}

INALCO

\section{Édition imprimée}

Date de publication : 1 juin 2011

Pagination : 297-300

ISBN : 978-2-85831-195-8

ISSN : $1164-5857$

\section{Référence électronique}

Yannick Maufroid, «Le temps et l'espace dans les récits de guerre de Shimao Toshio », Cipango [En ligne], 18 | 2011, mis en ligne le 25 septembre 2013, consulté le 30 juin 2021. URL : http:// journals.openedition.org/cipango/1626 ; DOl : https://doi.org/10.4000/cipango.1626

Ce document a été généré automatiquement le 30 juin 2021.

\section{(c) (1) \&}

Cipango est mis à disposition selon les termes de la Licence Creative Commons Attribution - Pas d'Utilisation Commerciale 4.0 International. 


\title{
Le temps et l'espace dans les récits de guerre de Shimao Toshio
}

\author{
Yannick Maufroid
}

\section{RÉFÉRENCE}

Yannick MAUFROID, Le temps et l'espace dans les récits de guerre de Shimao Toshio, mémoire de Master 2, sous la direction d'Anne Bayard-Sakai, INALCO, 2012.

1 Si les tokkōtai (ou kamikaze) laissèrent une large trace dans la mémoire de la guerre du Pacifique et dans la culture populaire, les récits de guerre de Shimao Toshio 島尾敏雄 (1917-1986) restent leur seul témoignage littéraire d'importance. Shimao fut commandant d'un escadron naval au sein des forces d'attaques spéciales, et sa mission fut de conduire des bateaux torpilles (shin.yō), chargés d'explosifs, à l'assaut des vaisseaux américains. Il fut affecté en octobre 1944 au sud de l'archipel d'Amami, sur l'île de Kakeromajima, après un an d'entraînement. Au bout de dix mois d'attente, il reçut son ordre de mission le 13 août 1945, ordre qui fut annulé deux jours plus tard par la capitulation sans condition du Japon.

Dans cette expérience passée comme il le dit lui-même «dans l'œil du cyclone de la guerre ", Shimao Toshio trouva un thème fécond d'inspiration littéraire, surtout, à l'instar d'autres auteurs entrés en littérature à la même époque, dans les premières années de l'après-guerre. Sa narration des événements présente toutefois un aspect éclaté, disparate et parcellaire qui la rend atypique au sein de la littérature japonaise de la guerre du Pacifique. Le récit autobiographique et réaliste de son déploiement sur Kakeromajima, commencé en 1949 avec Shutsu-kotōki 出孤島記 (Mémoires de la sortie de l'île), puis repris dans les années 1960 avec Shuppatsu wa tsui ni otozurezu 出発は遂に訪 れず (Le départ n'est jamais venu) puis Sono natsu no ima wa その夏の今は (En ces jours d'été) se poursuivra ainsi tardivement jusqu'aux dernières années de l'auteur.

D'autre part, les écrits de guerre de Shimao se caractérisent par une grande diversité narrative, puisqu'en dehors du récit des événements proprement dit, il a également 
écrit des récits dits "pastoraux ", s'attachant à décrire davantage la vie quotidienne sur Kakeromajima au milieu de ses habitants que les vicissitudes du conflit, ainsi que de nombreux récits de rêve qui pour certains insèrent des éléments de son expérience dans le flux de l'inconscient.

Il y a lieu de s'interroger sur la raison de cette discontinuité dans la narration et dans la diversité des formes. Peut-être faut-il y voir la marque d'un complexe rapport au temps et à l'espace qui caractériserait une telle expérience de guerre, et donnerait une difficulté particulière au fait de la relater. Le récit de guerre chez Shimao, est en effet privé d'action véritable. Son narrateur est ainsi un être passif, contraint à l'attente, à l'isolement et au confinement. Mais un récit ayant pour thème la guerre, même privé d'actes de guerre proprement dits, reste toujours empreint de la possibilité de l'action, qu'elle soit individuelle ou collective, et avec elle, de la perception du temps qui lui est propre. Cela est d'autant plus notable quand il s'agit de la guerre sous sa forme la plus destructrice, le sacrifice volontaire du tokkōtai. Mais dès lors que l'action ne se manifeste plus, c'est cette perception même du temps qui s'expose à nu en sa place, dominant la structure narrative du récit, confrontant mentalement un temps du quotidien dans lequel le narrateur s'enfonce paisiblement et le temps mythifié de l'action qui n'arrive pas. En étudiant la complexité de ces dynamiques temporelles sous toutes leurs facettes, et en les confrontant à la question connexe de l'espace, il s'agit aussi de voir comment elles évoluent selon la forme narrative que Shimao donne à son expérience.

5 L'étude se concentre sur un corpus d'une dizaine de textes, écrits entre 1946 et 1965, qui se rattachent aux trois grandes catégories auxquelles on rattache traditionnellement les récits de guerre de Shimao: le roman autobiographique et réaliste, (le premier essai en la matière que fut Tokunoshima kōkaiki 徳之島 航海記 (Journal d'un voyage vers Tokunoshima), puis la « trilogie » Shutsu-kotōki, Shuppatsu wa tsui ni otozurezu et Sono natsu no ima wa), qui constituera le cœur du corpus; les récits dits " pastoraux », au nombre de deux, Shima no hate 島の果て (Le bout de l'île) et Yoru no nioi 夜の匂い (L'odeur de la nuit); et enfin plusieurs récits de rêve, tels que Kotōmu 孤島夢 (Rêve d'une île), Asufaruto to kumo no kora アスファルトと蜘蛛の子ら (L'asphalte et les bébés araignées) ou encore Kizashi 兆 (Signes).

6 À travers l'analyse et la comparaison de ces textes, l'étude essaie ainsi de mettre en évidence que l'essentiel des récits de guerre de Shimao Toshio prend place dans le cadre d'un temps «mort ", où le narrateur-tokkōtai, abandonné du monde, n'ayant plus en tête que la perspective inéluctable d'une mission qui doit nécessairement le mener à la mort, est en quelque sorte forcé de vivre en étant déjà mort. Cependant, même «mort », il lui reste une mission à accomplir, si bien que le nécessaire maintien du corps et de l'esprit passe par la création d'un "quotidien» de guerre par l'intermédiaire des signes sensibles de son environnement. Au seuil des derniers jours de la guerre, ce quotidien se dissipe brusquement avec la disparition des bruits d'avion qui en constituaient le rythme, et plonge à la fois le narrateur dans le désarroi et dans une nouvelle expérience sensible, tournée cette fois vers l'île.

7 Ainsi coexistent dans les œuvres de guerre de Shimao, deux dichotomies, l'une temporelle entre quotidien et moment décisif (mission) et l'autre spatiale entre île et guerre. Ce sont précisément ces dichotomies que l'on retrouve dans les deux textes fictionnels et pastoraux que sont Shima no hate et Yoru no nioi, avec à chaque fois un point de vue différent. Dans Shima no hate, le récit est progressivement dirigé vers le 
moment décisif, où une guerre d'abord lointaine descend peu à peu sur l'île et rejoint les deux amants Saku et Toe " au bout de lîle » dans une scène dramatique. Dans Yoru no nioi, le héros Kiji tourne en rond sur l'île abandonnée, hanté par un quotidien de guerre inextricable et intemporel.

Ensuite vient le moment où ce binôme quotidien et moment décisif s'entrechoque, au cœur du récit réaliste, où la mission, longtemps imaginée par un narrateur angoissé à l'idée d'être "faux ", et vécue comme un simulacre insaisissable, est annoncée, avant d'être finalement hors d'atteinte. Au bout de cette éprouvante expérience où le temps semble s'accélérer puis revenir étrangement en arrière, le narrateur connaît le basculement salvateur dans l'après-guerre. Cependant, ce basculement reste incertain : sa perception du temps comme " circulaire ", "figé », le sentiment de rester " mort " quelque part, l'accompagne au-delà du cap du 15 août.

Mais à la question de savoir comment sortir de la guerre après une telle expérience, les récits de rêve de Shimao apportent également d'importants éléments de réponse. Ceux analysés dans l'étude confortent la vision d'une Histoire vécue comme un destin fatal, ou comme une stase éternelle qui écrase l'individu, mais, parallèlement, l'affranchissement des bornes spatio-temporelles du roman réaliste permet d'ouvrir la voie à un espace de liberté, à une réécriture venant remplir les «vides » traumatiques que laisse l'expérience de guerre. 